\title{
TECHNICAL-ECONOMIC STUDY OF THE FEED PER TOOTH INFLUENCE IN A CYLINDRICAL MILLING PROCESS OF ALLOYED STEELS
}

\author{
Milton F. Coba Salcedo ${ }^{1}$, Carlos Acevedo Peñaloza ${ }^{2}$, Guillermo Valencia Ochoa ${ }^{3 *}$ \\ ${ }^{1}$ Materials Engineering and Manufacturing Technology Research Group - IMTEF, Universidad del Atlántico, \\ Carrera 30 Número 8 - 49, Puerto Colombia - Colombia \\ ${ }^{2}$ Faculty of engineering, Universidad Francisco de Paula Santander, Cucuta - Colombia \\ ${ }^{3}$ Efficient Energy Management Research Group, Universidad del Atlántico, Carrera 30 Número 8 - 49, Puerto \\ Colombia - Colombia \\ guillermoevalencia@mail.uniatlantico.edu.co
}

\begin{abstract}
The economy of the machining process is an important point that has been given attention since the beginning of the process. For this reason, this study focuses on the evaluation of the performance of the cylindrical milling process, varying the feed rate per tooth for the operating conditions proposed in the revised case study. This was done using a calculation algorithm in which the fixed parameters were entered and the feed per tooth was varied. Finding benefits in terms of cutting speed, feed speed, cutting time and more. Increased feed per tooth resulted in lower process costs.
\end{abstract}

Keywords: avance, diente, fresado, costos, velocidad, corte.

\section{INTRODUCTION}

The worldwide desire to improve production systems has led researchers to seek the optimization of industrial processes. The manufacturing processes have not been alien to this, for this reason the milling process has been subjected to several studies over the years[1], in order to find the optimal conditions to carry out this process and thus obtain the best possible results.

One of the factors studied by the researchers has been shear force. This is important to achieve high quality products. It has been sought to predict the cutting force in corner milling by considering the instantaneous accuracy achievements of the tool coupling angle and the thickness of the undeformed chips[2]. In addition, on an austenitic stainless steel AISI 316L type, and a comparison is made between ascending and descending milling. The maximum values of the shear force, the resulting force or the maximum temperature are used to obtain qualitative and quantitative analyses[3].resulting in the fact that the main determining factor is not the thickness of the chip that is not instantly deformed.

On the other hand, a method was proposed to measure the equivalent residual stresses generated by milling, and on this basis the calculation of the deformation of the part was introduced[4]. Similarly, a system was presented to compensate for workpiece deformations in flexible peripheral milling based on piezoelectric actuators and their dynamic model[5], and a dynamic deformation model of the workpiece was constructed using the new method and the experiments are validated[6]. Showing these studies the importance of deformations in the milling process.

Likewise, the aim is to eliminate vibrations in the milling process because it affects the finish of the parts[7-8]. A feedback control system is used for this purpose, showing numerical results that reveal that the designed controller can efficiently suppress the vibrations of the milling process, as well as improve the stability of the cutting processes with the time delay entered[9]. $\mathrm{n}$ the same way, the milling process has been combined with turning, there are many parameters that affect the process, which makes it difficult to select the optimum one. Therefore the results presented in this study are used to select process parameters through multi-target optimization[10].

Taking all this into account, the contribution of this work is focused on evaluating the incidence of the variation in feed per tooth in a cylindrical milling process. Studying output parameters such as cutting speed, feed rate, chip volume, cutting time and associated costs and identifying the operating conditions under which the process is optimized paying attention to the output parameters studied. 


\section{METHODOLOGY}

A detailed description of the process is presented below, showing components of the process and explaining the cases of studies carried out, as well as fundamental equations that allowed the process variables to be calculated.

\subsection{Process description}

The study was conducted in a cylindrical milling process as shown in Figure 1. This process consists of the working material (1) and the milling cutter (2) which by means of its angular movement starts the material in each revolution.

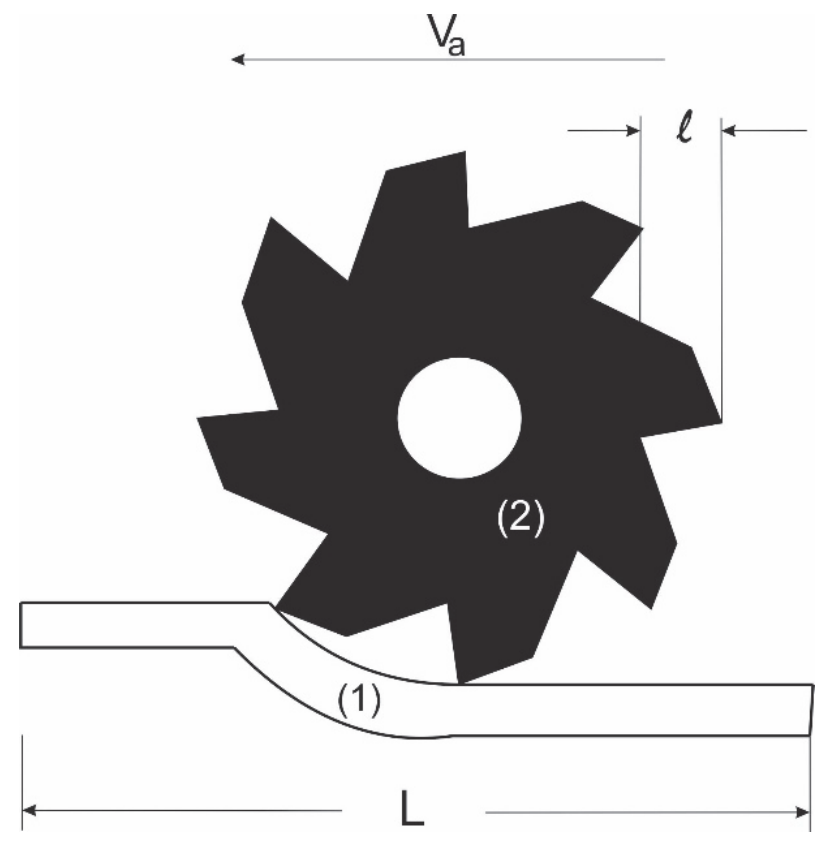

Figure 1. Process Diagram

For this process, a calculation algorithm was used in which the progress was varied and the values presented in Table 1were left fixed to evaluate their influence on the speeds and costs of the process.

Table 1. Parameters

\begin{tabular}{cc}
\hline Parameter & Value \\
\hline Length $(\mathrm{cm})$ & 50 \\
Thickness $(\mathrm{cm})$ & 9,2 \\
\hline Cutter diameter $(\mathrm{cm})$ & 12,5 \\
\hline Cost of tool $(\mathrm{US} \$ / \mathrm{h})$ & 36 \\
\hline Tool carrier cost $(\mathrm{US} \$ / \mathrm{h})$ & 55 \\
\hline Number plates & 22 \\
\hline Non productive time $(\mathrm{s})$ & 20 \\
\hline Machine and operator cost $(\mathrm{US} \$ / \mathrm{h})$ & 32 \\
\hline Number of pieces & 400 \\
\hline Depth $(\mathrm{mm})$ & 6 \\
\hline
\end{tabular}

\subsection{Fundamental Equations}

The equations presented here are the result of further research, have been duly validated and are widely used in the literature[11]. $\mathrm{n}$ this literature the milling time in the process is shown and is given by equation 1 , where $\mathrm{L}$ is the length of the part, $l$ is the length traveled by the cutter and $V_{a}$ is the feed rate

$$
t=\frac{L-l}{V_{a}} \text {. }
$$

On the other hand, $l$ can be calculated using equation 2 . Where $\mathrm{D}$ is the part diameter and $\mathrm{p}$ is the depth

$$
l=\sqrt{\left(\frac{D}{2}\right)^{2}-\left(\frac{D}{2}-p\right)^{2}} .
$$

Similarly, the feed rate meets equation 3 


$$
V_{a}=\frac{(a z)(z)(1000)(V)}{\pi D}
$$

An important parameter in machining is the volume of the chip, this does not help to know the amount of material removed from the workpiece, thus knowing the volume wasted. This value is given by equation 4

$$
\mathrm{V}=\frac{(a)(z)(p) V_{a}}{1000} \text {. }
$$

In order to reduce machining costs, there is the concept of minimum cost, which seeks a point at which the production of the parts is achieved from the lowest possible production cost values. Equation 5 is used to calculate the speed at which this point is reached

$$
V_{m c}=V_{1} \cdot\left(\frac{n}{1-n} \cdot \frac{X \cdot T_{1}}{\left(X \cdot t_{r f}+Y\right)}\right)^{n} .
$$

Where $\mathrm{n}$ is the number of revolutions, $\mathrm{X}$ is the operator and machine costs per unit time, $\mathrm{Y}$ is the cost per grinding, $\mathrm{V}_{1}$ speed limit and $t_{r f}$ is the tool reset time.

For tool life equation 5 is replaced by equation 5 in the Taylor line equation, thus achieving equation 6 .

$$
T_{m e}=\frac{1-n}{n} \cdot \frac{X \cdot t_{r f}+Y}{X} .
$$

Another important factor in machining is maximum production. The machining speed and minimum production time are also calculated for this with equation 7 and 8 respectively

$$
\begin{aligned}
& \mathrm{V}_{\mathrm{mp}}=\mathrm{V}_{1} \cdot\left[\mathrm{n} /(1-\mathrm{n}) \cdot \mathrm{T}_{1} / \mathrm{t}_{\mathrm{rf}}\right]^{\mathrm{n}} \\
& \mathrm{T}_{\mathrm{mp}}=(1-\mathrm{n}) / \mathrm{n} \cdot \mathrm{t}_{\mathrm{rf}} .
\end{aligned}
$$

\section{RESULTS AND ANALYSIS}

The influence of feed on speed parameters such as cutting speed and RPM can be seen in Figure 2. To visualize this, the feed rate per tooth was varied from 0.002 to 0.008 .

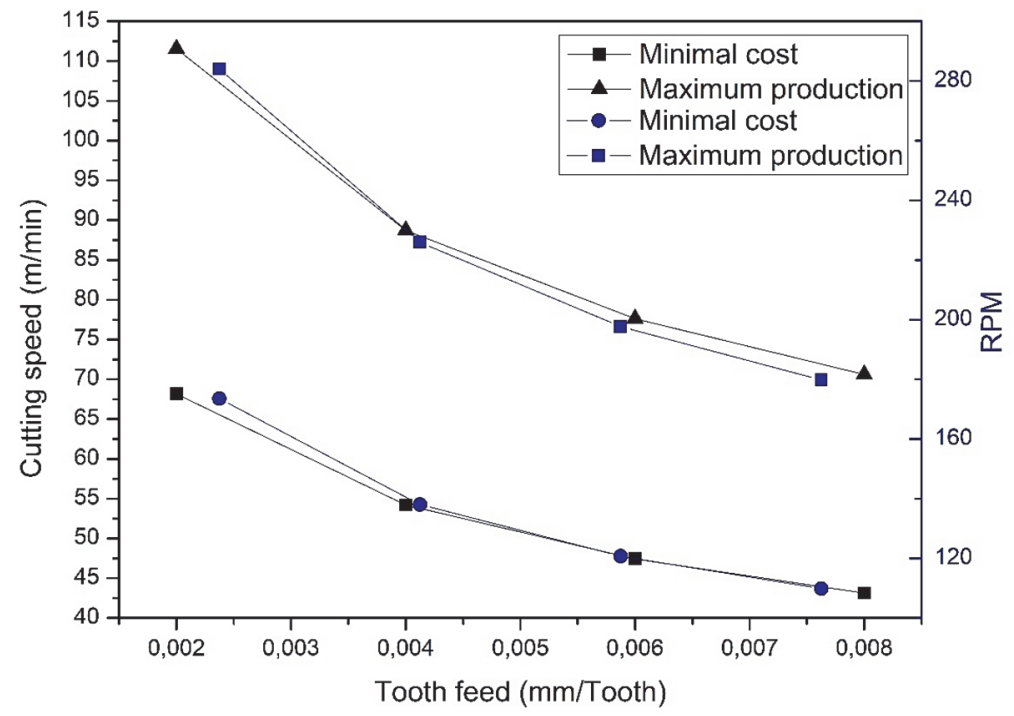

Figure 2. Cutting speed and RPM for each tooth feed rate

It is observed that as the feed rate per tooth increases, both the RPM and the cutting speed decrease, due to the fact that the volume of material pulled out per pass of the tooth increases, a greater power is needed to achieve this. This is most noticeable between 0.002 and 0.004 , after which the slope decreases. On the other hand, the minimum cost was reached at lower RPM and lower cutting speed.Similarly, the incidence of the variation in feed per tooth on parameters such as feed rate, chip volume and cutting time was studied. This is shown in the Figure 3. 


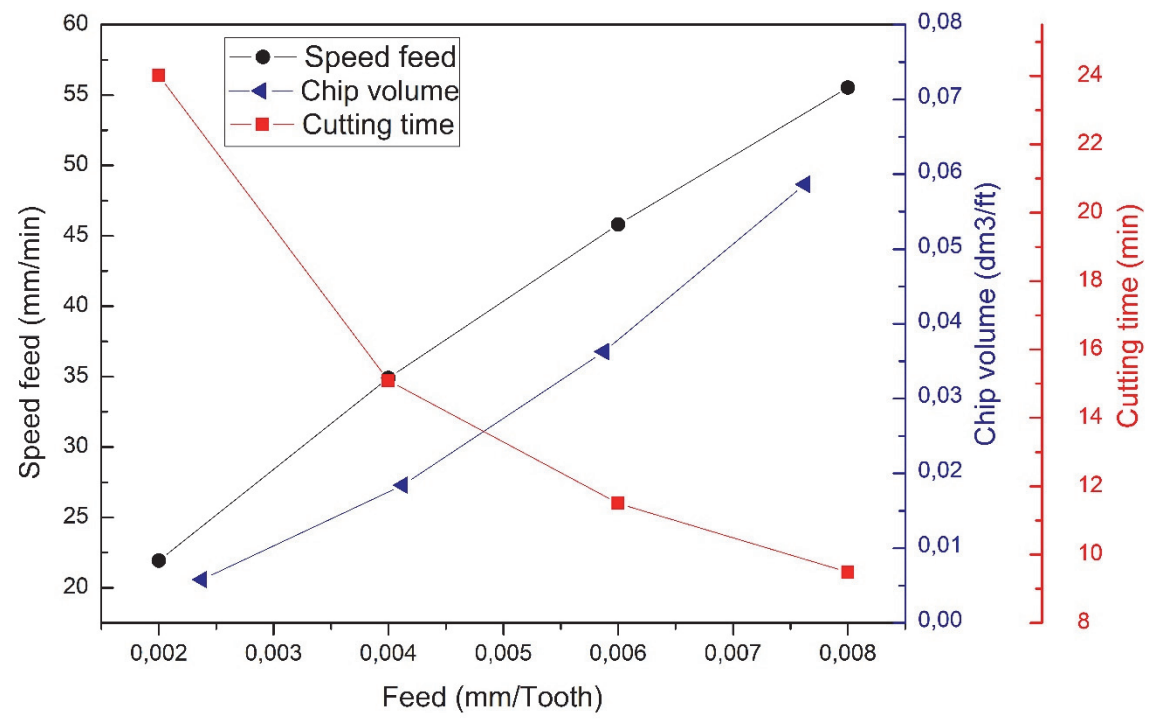

Figure 3. Feed rate, chip volume and cutting time

Here is shown as the feed per tooth increases as the feed rate per tooth increases. The volume of chips also increases because when there is a higher feed per tooth, it starts more material in each pass, thus increasing the volume of the material that is removed. The opposite is true of cutting time, which is reduced because each time a tooth is cut, the material that comes off faster is increased to the desired size.

On the other hand, tool costs and cutting times for feed rate variations per tooth were reviewed. In Figure 4 we can see that by increasing our study variable we can reduce the costs of both the tooling and the cutting time, due to the shorter cutting time reflected in Figure 3 thus reducing our costs.

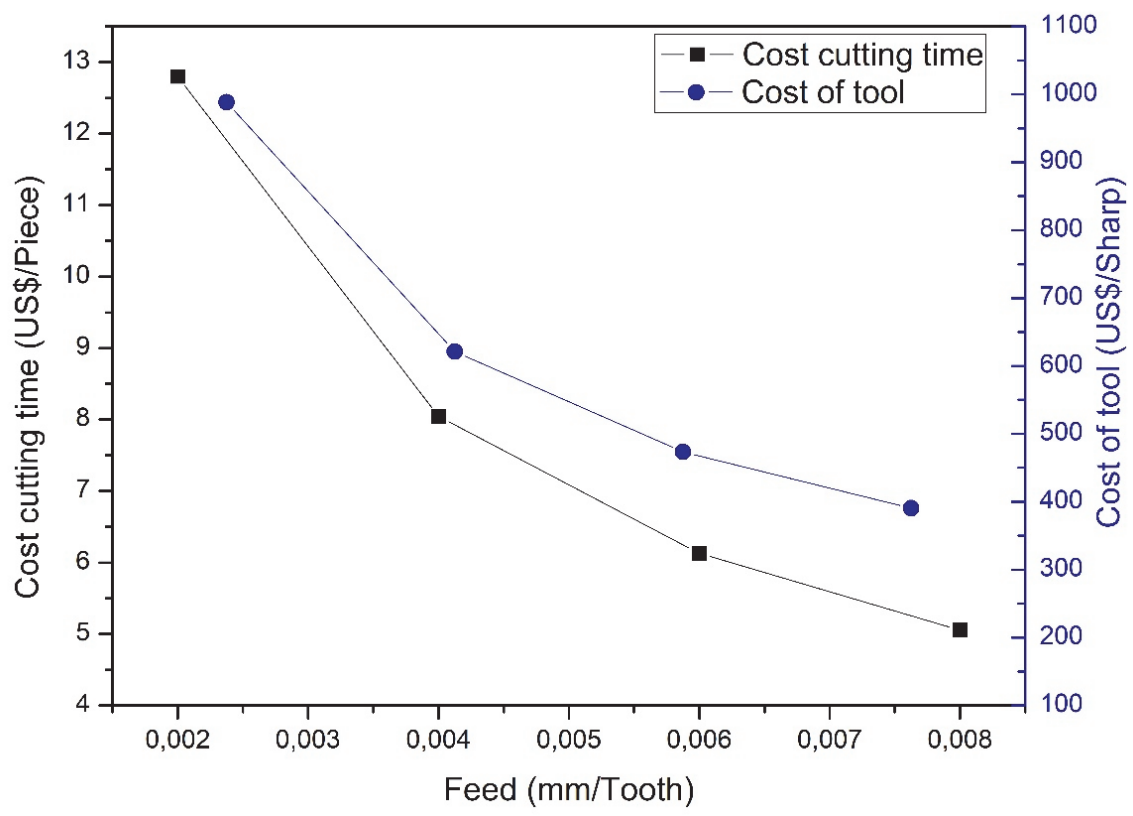

Figure 4. Cutting and tooling time costs

The only limitation of this is that by increasing the feed per tooth too much, we would induce too much stress on the teeth, causing a possible failure of the teeth, leading to the fracture and, consequently, increasing the downtime of the process, leading to unnecessary expenses.

\section{CONCLUSIONS}

Finally, it was concluded that by increasing the feed rate per tooth, the number of revolutions required for the milling process decreases considerably. In addition, it was demonstrated that increasing this progress brings us benefits such as shorter process times and higher cutting speed, which translates into lower process costs. This criterion cannot be abused due to the risk of tooth breakage, which is a serious problem for the milling process time and costs. 


\section{REFERENCS}

[1] G. Chryssolouris, N. Anifantis, and S. Karagiannis, "Laser Assisted Machining: An Overview," J. Manuf. Sci. Eng., vol. 119, no. 4B, pp. 766-769, Nov. 1997.

[2] X. Han and L. Tang, "Precise prediction of forces in milling circular corners," Int. J. Mach. Tools Manuf., vol. 88, pp. 184-193, 2015.

[3] M. San-Juan, Ó. Martín, M. del P. de Tiedra, F. J. Santos, R. López, and J. A. Cebrián, "Study of Cutting Forces and Temperatures in Milling of AISI 316L," Procedia Eng., vol. 132, pp. 500-506, 2015.

[4] L. Meng, M. Atli, and N. He, "Measurement of equivalent residual stresses generated by milling and corresponding deformation prediction," Precis. Eng., vol. 50, pp. 160-170, 2017.

[5] E. Diez, E. Leal-Muñoz, H. Perez, and A. Vizan, "Dynamic analysis of a piezoelectric system to compensate for workpiece deformations in flexible milling,” Mech. Syst. Signal Process., vol. 91, pp. 278-294, 2017.

[6] J. Fei et al., "Investigation of moving fixture on deformation suppression during milling process of thin-walled structures," J. Manuf. Process., vol. 32, pp. 403-411, 2018.

[7] K. J. Kalinski and M. A. Galewski, "Optimal spindle speed determination for vibration reduction during ball-end milling of flexible details,” Int. J. Mach. Tools Manuf., vol. 92, pp. 19-30, 2015.

[8] H. Moradi, G. Vossoughi, M. Behzad, and M. R. Movahhedy, "Vibration absorber design to suppress regenerative chatter in nonlinear milling process: Application for machining of cantilever plates," Appl. Math. Model., vol. 39, no. 2, pp. 600-620, 2015.

[9] X. Long, S. Ren, and P. Zheng, "Delayed State Feedback Control for Milling Process," Procedia IUTAM, vol. 22, pp. 115-122, 2017.

[10] M. E. Kara and E. Budak, "Optimization of Turn-milling Processes," Procedia CIRP, vol. 33, pp. 476-483, 2015.

[11] M. Groover, FUNDAMENTOS DE MANUFACTURA MODERNA, Mc Graw Hi. Mc Graw Hill, 2017. 